\title{
Article \\ Putrescine Depletion Affects Arabidopsis Root Meristem Size by Modulating Auxin and Cytokinin Signaling and ROS Accumulation
}

\author{
Ahmed M. Hashem ${ }^{1,2,3,+}$, Simon Moore ${ }^{1,4,+}$, Shangjian Chen ${ }^{1}$, Chenchen Hu ${ }^{1}$, Qing Zhao ${ }^{1}$, \\ Ibrahim Eid Elesawi ${ }^{1,2,5}{ }^{\mathbb{D}}$, Yanni Feng ${ }^{1}$, Jennifer F. Topping ${ }^{4}$, Junli Liu ${ }^{4} \mathbb{D}$, Keith Lindsey ${ }^{4}$ \\ and Chunli Chen $1,2, *$ (D)
}

\section{check for} updates

Citation: Hashem, A.M.; Moore, S. Chen, S.; Hu, C.; Zhao, Q.; Elesawi, I.E.; Feng, Y.; Topping, J.F.; Liu, J.; Lindsey, K.; et al. Putrescine Depletion Affects Arabidopsis Root Meristem Size by Modulating Auxin and Cytokinin Signaling and ROS Accumulation. Int. J. Mol. Sci. 2021, 22, 4094. https://doi.org/ 10.3390/ijms22084094

Academic Editor: Jen-Tsung Chen

Received: 5 March 2021

Accepted: 12 April 2021

Published: 15 April 2021

Publisher's Note: MDPI stays neutral with regard to jurisdictional claims in published maps and institutional affiliations.

Copyright: (c) 2021 by the authors. Licensee MDPI, Basel, Switzerland. This article is an open access article distributed under the terms and conditions of the Creative Commons Attribution (CC BY) license (https:// creativecommons.org/licenses/by/ $4.0 /)$.
1 College of Life Science and Technology, Huazhong Agricultural University, Wuhan 430070, China; ahmedhashem@webmail.hzau.edu.cn (A.M.H.); simon.moore@durham.ac.uk (S.M.); chenshangjian@webmail.hzau.edu.cn (S.C.); xccb456@webmail.hzau.edu.cn (C.H.); qing.zhao@webmail.hzau.edu.cn (Q.Z.); ibrahimeid@webmail.hzau.edu.cn (I.E.E.); feng@mail.hzau.edu.cn (Y.F.)

2 Key Laboratory of Plant Resource Conservation and Germplasm Innovation in Mountainous Region (Ministry of Education), Institute of Agro-Bioengineering, College of Life Science, Guizhou University, Guiyang 550025, China

3 Biotechnology Department, Faculty of Agriculture, Al-Azhar University, Cairo 11651, Egypt

4 Department of Biosciences, Durham University, South Road, Durham DH1 3LE, UK; j.f.topping@durham.ac.uk (J.F.T.); junli.liu@durham.ac.uk (J.L.); keith.lindsey@durham.ac.uk (K.L.)

5 Agricultural Biochemistry Department, Faculty of Agriculture, Zagazig University, Zagazig 44511, Egypt

* Correspondence: chenchunli@mail.hzau.edu.cn

+ These authors contributed equally to this work.

\begin{abstract}
Polyamines (PAs) dramatically affect root architecture and development, mainly by unknown mechanisms; however, accumulating evidence points to hormone signaling and reactive oxygen species (ROS) as candidate mechanisms. To test this hypothesis, PA levels were modified by progressively reducing ADC1/2 activity and Put levels, and then changes in root meristematic zone (MZ) size, ROS, and auxin and cytokinin (CK) signaling were investigated. Decreasing putrescine resulted in an interesting inverted-U-trend in primary root growth and a similar trend in MZ size, and differential changes in putrescine (Put), spermidine (Spd), and combined spermine (Spm) plus thermospermine (Tspm) levels. At low Put concentrations, ROS accumulation increased coincidently with decreasing MZ size, and treatment with ROS scavenger KI partially rescued this phenotype. Analysis of double AtrbohD/F loss-of-function mutants indicated that NADPH oxidases were not involved in $\mathrm{H}_{2} \mathrm{O}_{2}$ accumulation and that elevated ROS levels were due to changes in PA back-conversion, terminal catabolism, PA ROS scavenging, or another pathway. Decreasing Put resulted in a non-linear trend in auxin signaling, whereas CK signaling decreased, re-balancing auxin and CK signaling. Different levels of Put modulated the expression of PIN1 and PIN2 auxin transporters, indicating changes to auxin distribution. These data strongly suggest that PAs modulate MZ size through both hormone signaling and ROS accumulation in Arabidopsis.
\end{abstract}

Keywords: polyamine; root meristem; hormone signaling; ROS; auxin response; PIN transporter; cytokinin response

\section{Introduction}

Polyamines (PAs) are small polycationic compounds found in all living organisms. Due to their characteristic positive charges, they can interact with negatively charged molecules such as DNA, RNA, proteins, and phospholipids, and therefore influence their activity [1]. Putrescine (Put), spermidine (Spd), spermine (Spm), and thermospermine (Tspm) are the most common polyamines found in plants [2,3]. PAs have been shown to be implicated in the regulation of several plant physiological processes, including 
flower development, embryogenesis, organogenesis, senescence, and fruit maturation and development [4], and are also involved in Arabidopsis meristem development [5] and stress responses [6-8]. Recent studies on plant polyamines have been reviewed [9]. Put is the central diamine substrate compound for the biosynthesis of higher triamine and tetraamine polyamines. Unlike many other plants, Arabidopsis thaliana has only one Put biosynthesis pathway, through arginine decarboxylase [10]. In Arabidopsis, arginine decarboxylase 1 (ADC1) and ADC2 are key rate-limiting enzymes in Put synthesis, which catalyze L-arginine conversion into Put [10]. It was recently reported that the $A D C 1$ gene is involved in $N$-acetylputrescine biosynthesis from $N \delta$-acetylornithine [11].

Cellular PA homeostasis is controlled by a combination of mechanisms, including transcriptional and upstream open reading frames (uORFs), translational regulation of PA biosynthesis genes, conjugation, back-conversion, and terminal catabolism [12-14]. The intricacies of PA biosynthesis are exhibited by several examples-treatment with D-Arg, the ADC-specific competitive inhibitor, results in a reduction in Put and increased Spd and Spm content in Pringlea antiscorbutica [15]; adc2 mutants with low Put content show no change in Spd and Spm levels [16]; overexpression of $A D C$ in plants generally results in high Put accumulation but in many cases exhibits relatively small changes in Spd and Spm [17]; and silencing of $A D C$ genes significantly reduces Put, Spd, and Spm + Tspm in Arabidopsis ecotype Wassilewskija (Ws) [18]. This indicates that PA levels are under strict regulation [19] and emphasizes the complexity of the PA metabolic pathway.

Modifications in PA content can differentially affect root growth and development. For example, treatment with D-Arginine (D-Arg), a specific ADC1/2 competitive inhibitor, leads to a reduction in Put and a longer primary root length in Pringlea antiscorbutica [15]; perturbation of Put biosynthesis in $a d c 1$ and adc2 single T-DNA mutants shows no root phenotype, whereas the double mutant is lethal [20]; mutation in BUD2 gene, which encodes S-adenosylmethionine decarboxylase 4 (SAMDC4), a key enzyme required for PA biosynthesis in A. thaliana, resulted in Put accumulation and altered root architecture [21]; silencing both $A D C 1$ and $A D C 2$ shows a significant reduction in primary root length [18], and high levels of Put treatment exhibit a similar phenotype in Arabidopsis [22]. Exogenous application of low levels of Put has no effect on root growth in Arabidopsis $[23,24]$, but treatment with $1 \mathrm{mM}$ Put increases root length in strawberries [25]. Treatment with an inhibitor of Tspm biosynthesis increased primary root growth, whereas treatment with exogenous Tspm inhibited root growth [26]; and inhibition or induction of Arabidopsis polyamine oxidase 5 (AtPAO5) significantly affected root length and development [27]. Such findings indicate complex regulatory effects of PAs on root development.

The PA back-conversion and terminal catabolism processes are mediated by two classes of amine oxidases, copper-containing amine oxidases (CuAOs) and FAD-dependent polyamine oxidases (PAOs). These enzymatic reactions lead to the production of $\mathrm{H}_{2} \mathrm{O}_{2}$ [8,28-30], suggesting another mechanism by which PAs can affect root growth and development [28], in addition to their role as ROS scavengers [31], acting to reduce stress-induced ROS accumulation in leaves and roots [32,33].

ROS homeostasis plays a vital role in root growth and development. A study of how changes in ROS accumulation affect root development [34] reported that the balance between hydrogen peroxide $\left(\mathrm{H}_{2} \mathrm{O}_{2}\right)$ and superoxide $\left(\mathrm{O}_{2}{ }^{-}\right)$affects root growth and meristem structure by influencing the transition from cell division to cell differentiation. It was also demonstrated that perturbation of polyamine catabolism ZmPAO1 strongly influences root development and xylem differentiation in Zea mays, mediated by $\mathrm{H}_{2} \mathrm{O}_{2}$ production [35]. Such studies suggest that altering ROS homeostasis is one mechanism by which PAs could affect root development.

Several studies indicate that PAs also modify hormone response and crosstalk under specific physiological and developmental processes [36,37]; for example, transcriptome studies revealed that changes in endogenous PA content altered the expression levels of genes associated with biosynthesis and signaling of several plant hormones such as auxin, ethylene, and gibberellins [38]; it is necessary for interactions between Tspm, auxin, and 
cytokinin to be tightly controlled for proper xylem development and plant growth [27]; PAs and auxin affect root growth and development in two sweet orange cultivars [39]; and several studies have further explored the relationships between PAs and auxin response [40]. The above data provide evidence to suggest that the adjustment of the hormone response is an additional mechanism by which PAs affect root development.

The above studies demonstrate that changes in PA levels can influence plant phenotypes in multiple species and tissues; however, mechanisms linking PA levels to phenotype are not well understood. In this work, we focus on the root meristem to identify PA-driven mechanisms that regulate the meristem phenotype under conditions of Put depletion in Arabidopsis.

\section{Results}

Since $a d c 1$ and $a d c 2$ single T-DNA mutants exhibit no root phenotype (Figure 1A,C) and the double mutant is lethal, it was decided to adjust PA levels by simultaneously reducing the activity of $\mathrm{ADC} 1$ and $\mathrm{ADC} 2$, which are key enzymes in the Put biosynthesis pathway. Several previous studies [41-46] have used D-Arg treatment to inhibit ADC1/2 and deplete Put levels. We progressively reduced Put biosynthesis, the substrate of Spd, Spm, and Tspm, by inhibiting ADC1/2 enzyme activity using the competitive inhibitor D-Arg, which specifically inhibits ADC1/2 activity by blocking binding of the Put substrate L-Arg. Given the specificity of D-Arg and its mode of action, this method was thought to be equivalent to using ADC genetic knockdowns, with the additional advantage of allowing improved flexibility in the control over ADC activity and Put biosynthesis.

$A D C 2:: G U S$ results confirmed the differential localization of ADC2 expression to the root (Figure 1D). The results also suggested that ADC2 activity is higher in the root than that of ADC1, since while D-Arg treatment inhibited root length in WT, adc1, and adc2, DArg inhibition of ADC1 activity in the adc2 mutant resulted in a shorter root than inhibition of $\mathrm{ADC} 2$ did in the $a d c 1$ mutant, indicating that the adc2 mutant root phenotype is more sensitive to D-Arg than adc1 (Figure 1B,C).

\subsection{D-Arg Application Promotes or Inhibits Root Growth and Meristem Size in a Concentration-Dependent Manner}

To explore how Put depletion modulates root growth and development, we treated 5-day-old Arabidopsis wild-type Col-0 seedlings for a further 3 days with a range of concentrations from $0.01 \mathrm{mM}$ to $1 \mathrm{mM}$ D-Arg, a competitive inhibitor of ADC1/2 activity (Figure 2A,B). To determine the effect of D-Arg on polyamine content, seedlings were treated with $0.01,0.05,0.1$, and $0.6 \mathrm{mM}$ of D-Arg for three days. Whole seedlings were used for HPLC analysis. Data revealed a significant reduction in Put of approximately 30-35\% upon $0.01,0.05$, and $0.1 \mathrm{mM}$ treatment, and then a significant decrease of approximately $60 \%$ upon $0.6 \mathrm{mM}$ treatment. The Spm plus Tspm concentration was unchanged with $0.01 \mathrm{mM}$ D-Arg treatment, and it increased by $78 \%$ at $0.05 \mathrm{mM}$, by $100 \%$ at $0.1 \mathrm{mM}$, and then only by $35 \%$ at $0.6 \mathrm{mM}$ treatment, relative to controls (Figure 2A). Interestingly, Spd remained stable until a considerable decrease in Put occurred at $0.6 \mathrm{mM}$ D-Arg, when Spd declined by approximately $50 \%$ (Figure 2A). Spd levels appeared to be more tightly controlled than for Put and Spm + Tspm.

After 3 days of treatment, we observed an inverted-U trend in root growth as D-Arg concentrations increased (Figure 2B,C). Compared to controls, root growth was unchanged at $0.01 \mathrm{mM}$ and $0.05 \mathrm{mM}$ treatments, enhanced at $0.1 \mathrm{mM}$, unchanged at $0.3 \mathrm{mM}$, and then root growth gradually decreased at treatment concentrations of $0.6 \mathrm{mM}$ and greater.

During the 3-day D-Arg treatment period, we observed interesting changes in daily root growth as demonstrated by the new root growth-rate curve (Figure 2C). We noticed no significant change in root length at concentrations from 0.01 to 0.6 after one day of treatment, whereas 0.8 and $1 \mathrm{mM}$ showed a significant decrease. However, the root growth rate increased at days two and three at $0.1 \mathrm{mM}$ and then started to decline at 0.8 and $1 \mathrm{mM}$. The root reduction on day three became highly significant, at $0.6 \mathrm{mM}$ and more, compared to untreated controls. 
A

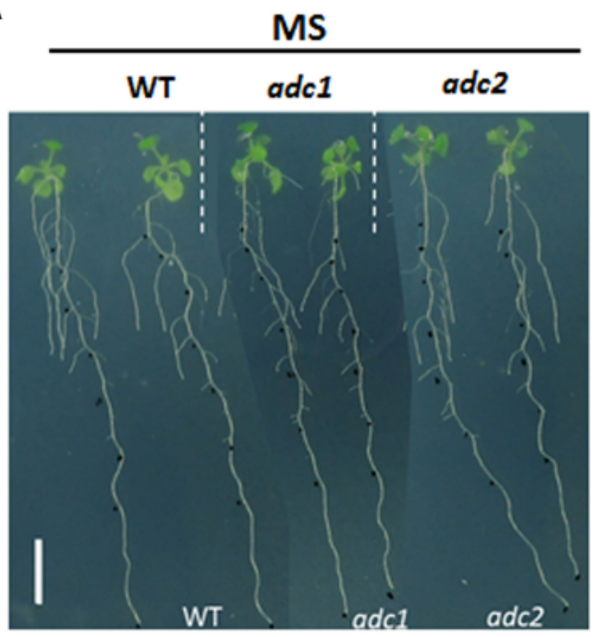

C

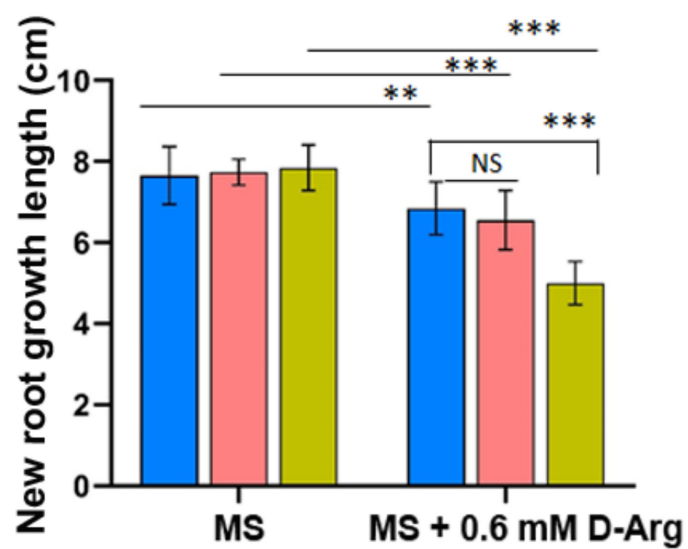

B

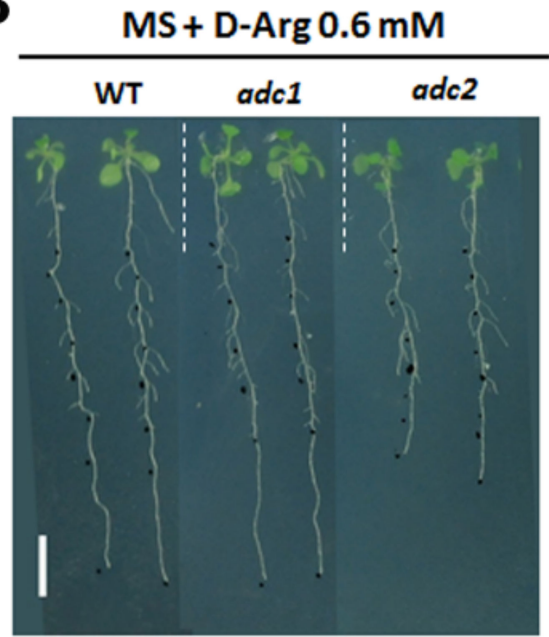

D

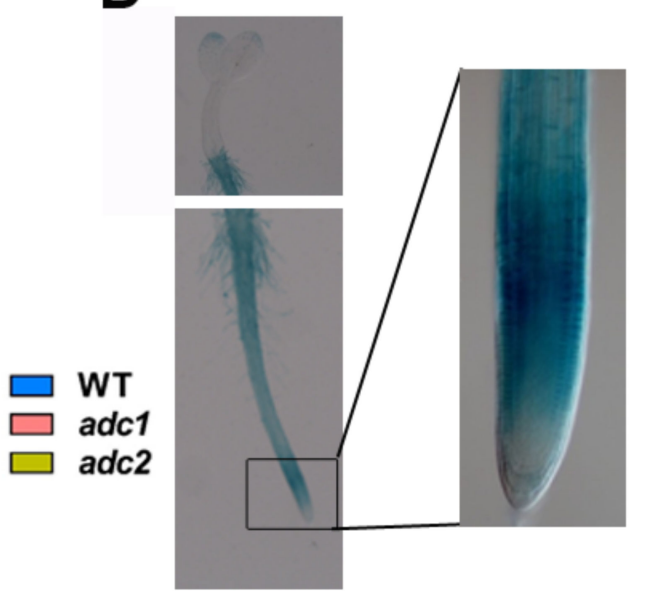

Figure 1. $a d c 1$ and $a d c 2$ single mutants exhibit no root phenotype and the results indicate that ADC2 localizes mainly to the root and adc2 is more sensitive to D-Arg than adc1. For (A), (B) and (C), 5-day-old seedlings at the same developmental stage were transferred to new media containing water (Ctrl) or $0.6 \mathrm{mM}$ D-Arg and were treated for 8 days. (A) Untreated wild-type (WT), adc1, and adc2 root phenotypes are the same. Scale bar $=1 \mathrm{~cm}$. (B) D-Arg treatment inhibits root length of WT, adc1, and adc2. Scale bar = $1 \mathrm{~cm}$. (C) D-Arg treatment exhibits no difference between WT and adc1 root length; however, the adc2 root is significantly shorter that of WT and adc1 phenotypes. (D) Histochemical localization of GUS activity in 2-day-old transgenic seedling harboring promoter ADC2::GUS (pAtADC2::GUS). Data shown are averages \pm SD (n > 30). Asterisks denote significant differences $\left({ }^{* *} p<0.01,{ }^{* * *} p<0.001\right.$; Student's $t$-test).

Root growth is the result of both cell division in the meristem zone (MZ) and cell expansion in the elongation zone [47]. We chose to more closely examine the meristem structure under D-Arg treatments with a series concentration (Figure 2D) and measured the meristem length and number of cells in the MZ cortical layer. Root cells were analyzed by means of differential interference contrast (DIC) microscopy and compared to the untreated control. A medium D-Arg concentration of $0.1 \mathrm{mM}$ enlarged the meristem by approximately $18 \%$, and MZ size decreased by $20 \%$ at $0.6 \mathrm{mM}$ D-Arg and by $25 \%$ at $0.8 \mathrm{mM}$ D-Arg (Figure 2E). The MZ cell number slightly increased, but not significantly, at $0.1 \mathrm{mM}$ and then decreased significantly at 0.6 and $0.8 \mathrm{mM}$ D-Arg (Figure 2F). 
A

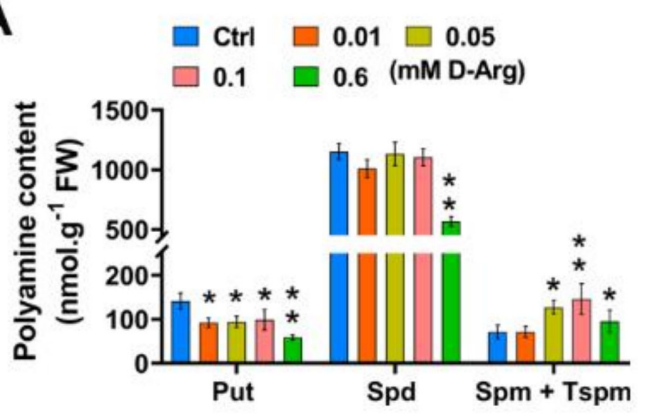

C

- Ctrl $=0.01+0.05>0.1$

$0.3 \circ 0.6=0.8 \circ 1$ (mM D-Arg)

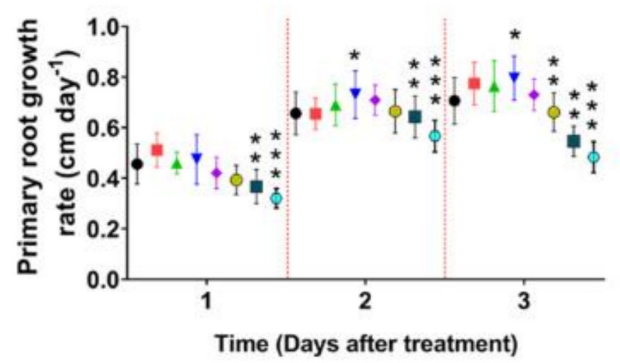

E

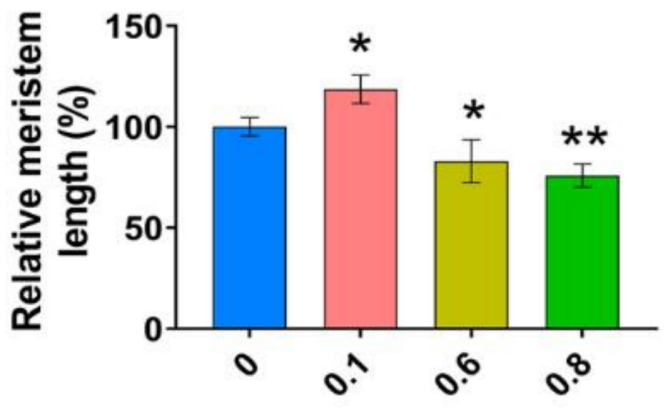

D-Arg concentration (mM)
B

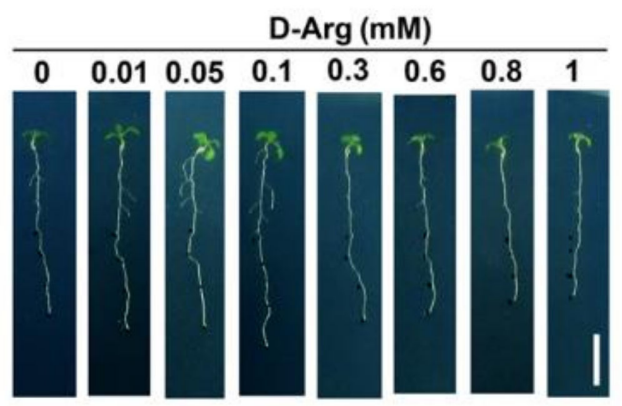

D

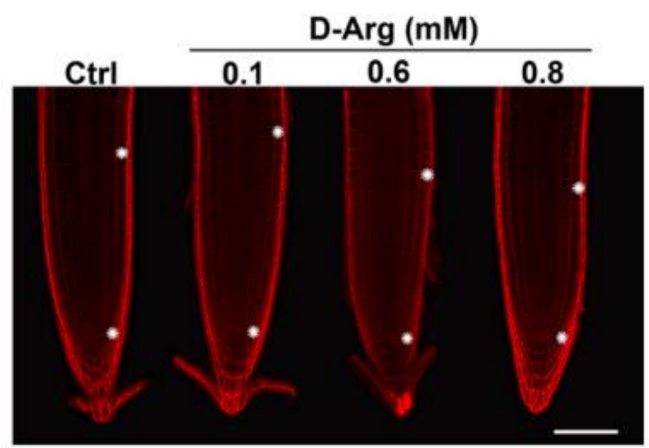

$\mathbf{F}$

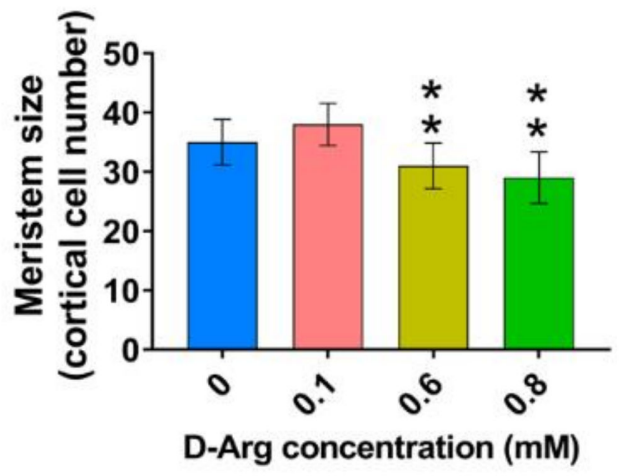

Figure 2. ADC1/2 inhibition differentially modifies polyamine (PA) content and affects root growth and meristematic zone (MZ) size in a non-linear concentration-dependent manner. Five-day-old seedlings at the same developmental stage were transferred to new media containing water (Ctrl) or D-Arg and were treated for 3 days. (A) Differential effect of D-Arg treatment on polyamine content. Putrescine (Put), spermidine (Spd), and spermine plus thermo-spermine (Spm + Tspm) levels were measured using HPLC. (B) Whole seedling phenotype shows a non-linear effect of increased D-Arg treatment. Scale bar $=1 \mathrm{~cm}$. (C) Daily new root growth length varies for different D-Arg concentrations. (D) Root meristem imaging, using PI staining and confocal microscopy, exhibits the non-linear effects of D-Arg on MZ size. Two white asterisks on each root indicate the quiescent center (QC) (bottom) and first elongated cell (top). Scale bar $=100 \mu \mathrm{m}$. (E) Meristem cell length normalized to control. (F) Cortical cell number in the meristem zone. Data shown are averages \pm SD (n $>30)$. Asterisks denote significant differences compared with the control $\left({ }^{*} p<0.05,{ }^{* *} p<0.01\right.$; Student's $t$-test).

\subsection{KI Application Indicates That MZ Size Inhibition at High D-Arg Concentration Is Partially Due to $\mathrm{H}_{2} \mathrm{O}_{2}$ Accumulation}

To investigate whether treatment with different D-Arg concentrations alters ROS accumulation in WT seedlings, we used 3,3'-diaminobenzidine (DAB) (Figure 3A) and nitrotetrazolium blue (NBT) (Figure 3C) staining to detect the presence of $\mathrm{H}_{2} \mathrm{O}_{2}$ and $\mathrm{O}_{2}{ }^{-}$ respectively in vivo. DAB staining indicated no difference in ROS accumulations at low and medium D-Arg treatment, but at high D-Arg treatment of $0.6 \mathrm{mM}$ and $0.8 \mathrm{mM}$, ROS 
increased significantly (Figure 3B). Furthermore, we did not detect significant changes in NBT staining at any D-Arg concentration (Figure 3D).

A

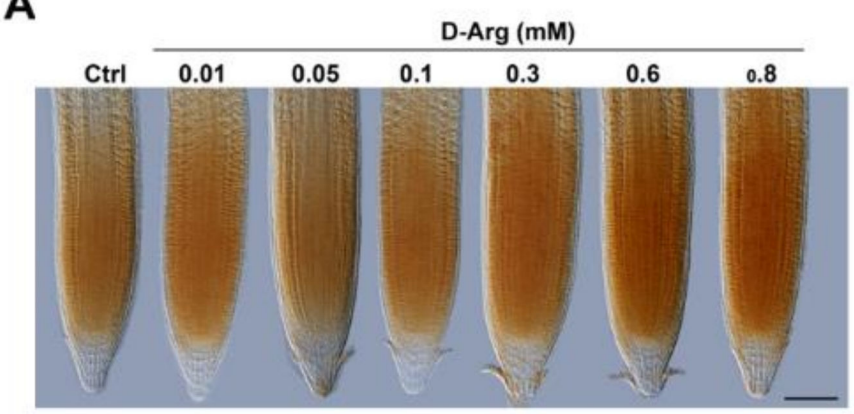

C

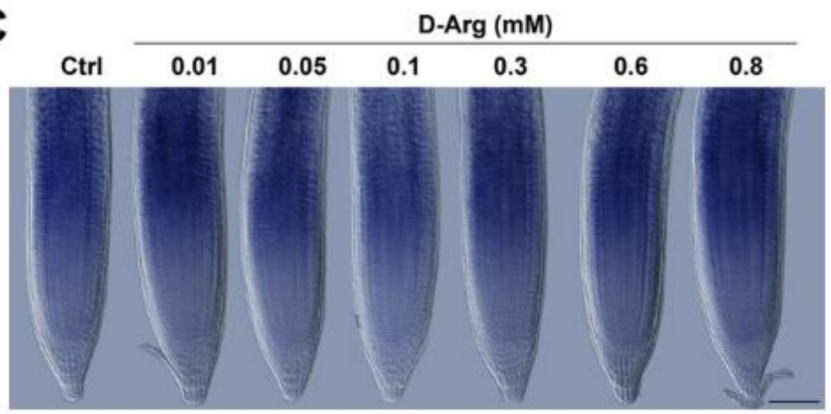

E
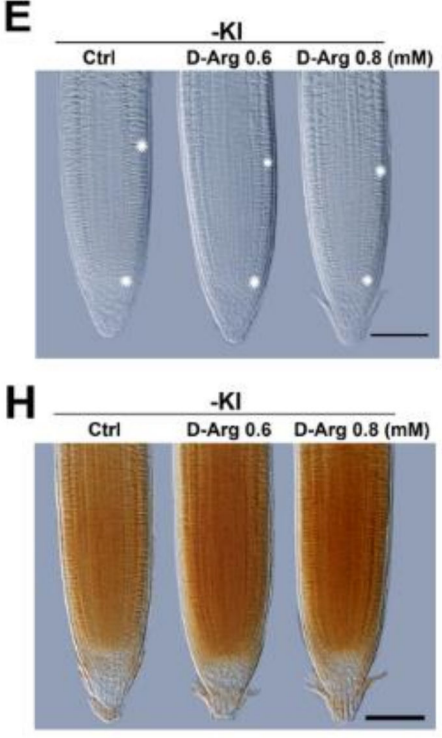
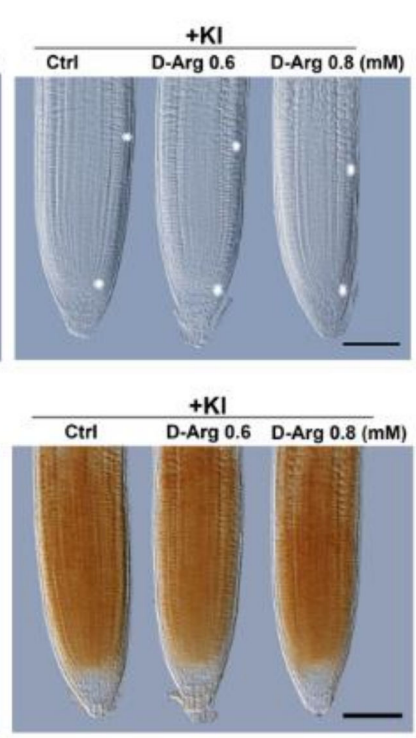

B

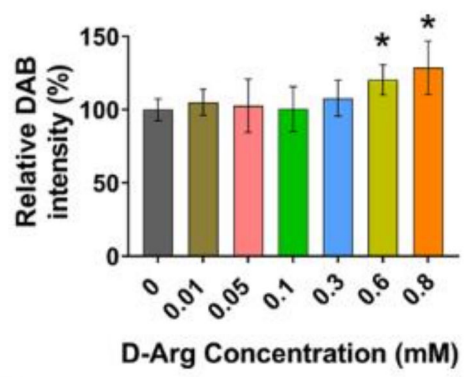

D
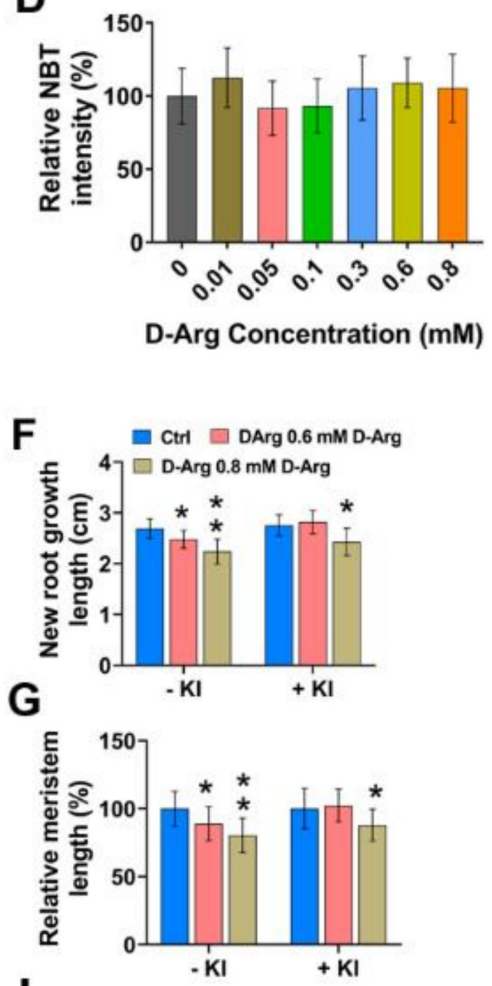

I

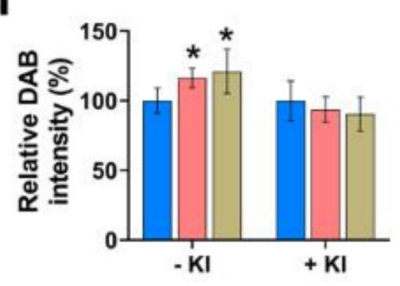

Figure 3. D-Arg-induced $\mathrm{H}_{2} \mathrm{O}_{2}$ accumulation, root length, and $\mathrm{MZ}$ size reduction is partially rescued by ROS scavenging with $1 \mathrm{mM} \mathrm{KI}$. Five-day-old seedlings at the same developmental stage were transferred to new media containing water (Ctrl) or D-Arg and treated for 3 days. MZ imaging by differential interference contrast (DIC) microscopy. (A,B) 3,3'diaminobenzidine (DAB) staining and relative stain intensity indicate that D-Arg treatment increases $\mathrm{H}_{2} \mathrm{O}_{2}$ accumulation in root meristem. (C,D) Nitrotetrazolium blue (NBT) staining and relative stain intensity indicates that D-Arg treatment does not change $\mathrm{O}_{2}{ }^{-}$accumulation in the root meristem. (E-G) Treatment with and without D-Arg and $1 \mathrm{mM} \mathrm{KI}$ shows partial rescue of root meristem and root length by KI. (H,I) DAB staining of root meristem and relative stain intensity, with or without D-Arg and KI, show successful $\mathrm{H}_{2} \mathrm{O}_{2}$ scavenging by KI. All scale bars $=100 \mu \mathrm{m}$. Data shown are averages $\pm \mathrm{SD}$ ( $\mathrm{n}>30)$. Asterisks indicate significant differences compared with the control $\left({ }^{*} p<0.05,{ }^{* *} p<0.01\right.$; Student's $t$-test). 
To determine whether the reduction in root length and root meristem at higher D-Arg concentrations was attributable to $\mathrm{H}_{2} \mathrm{O}_{2}$ accumulation, we exposed control roots and roots treated with $0.6 \mathrm{mM}$ and $0.8 \mathrm{mM}$ D-Arg to the ROS scavenger potassium iodide (KI, $1 \mathrm{mM}$ ), as described previously [34]. KI application successfully scavenged $\mathrm{H}_{2} \mathrm{O}_{2}$ (Figure $3 \mathrm{H}, \mathrm{I}$ ) and completely rescued the shorter root phenotype caused by $0.6 \mathrm{mM}$ of D-Arg treatment, whereas at $0.8 \mathrm{mM}$ D-Arg, root length and meristem size were only partially recovered (Figure $3 \mathrm{E}-\mathrm{G}$ ), suggesting that at higher D-Arg levels, reduced root length is not completely ROS-dependent and that other factors are involved.

\section{3. $\mathrm{H}_{2} \mathrm{O}_{2}$ Accumulation Is Not Caused by NADPH Oxidases}

During plant growth and development, ROS are predominantly generated by the NADPH oxidases RBOHD and RBOHF class III peroxidases [48,49] and polyamine amine oxidases (PAO) [8]. Some reports show a link between PAs and NADPH oxidases (RBOHD/F) in tobacco and Arabidopsis [50,51]. To investigate the involvement of NADPH oxidases in $\mathrm{H}_{2} \mathrm{O}_{2}$ accumulation at high D-Arg treatments, we examined the phenotype of seedlings carrying double atrbohD/F loss-of-function mutants. In this set of experiments, the D-Arg treatment period was extended from 3 to 6 days and new root growth length was observed to ensure that NADPH oxidases were not a significant source of ROS accumulation under conditions of Put depletion. The results showed that, similarly to the WT results, exogenous high D-Arg application inhibited the new root growth of atrbohD/F (Figure 4A,B).

A

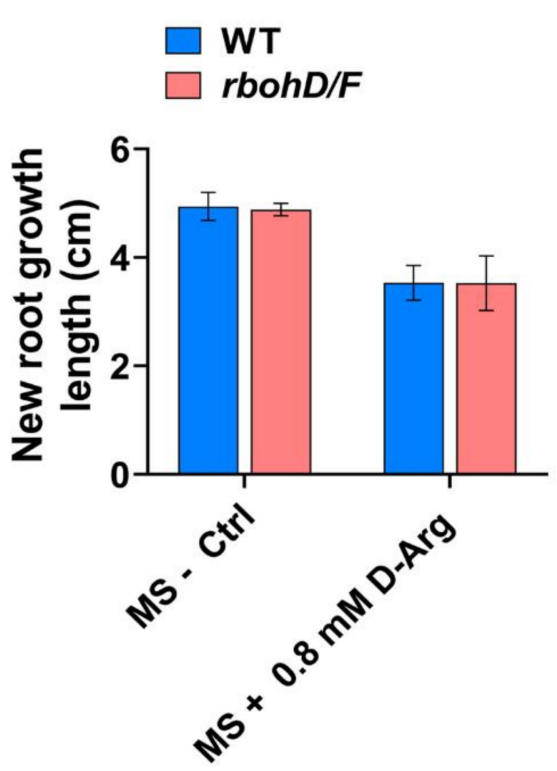

B

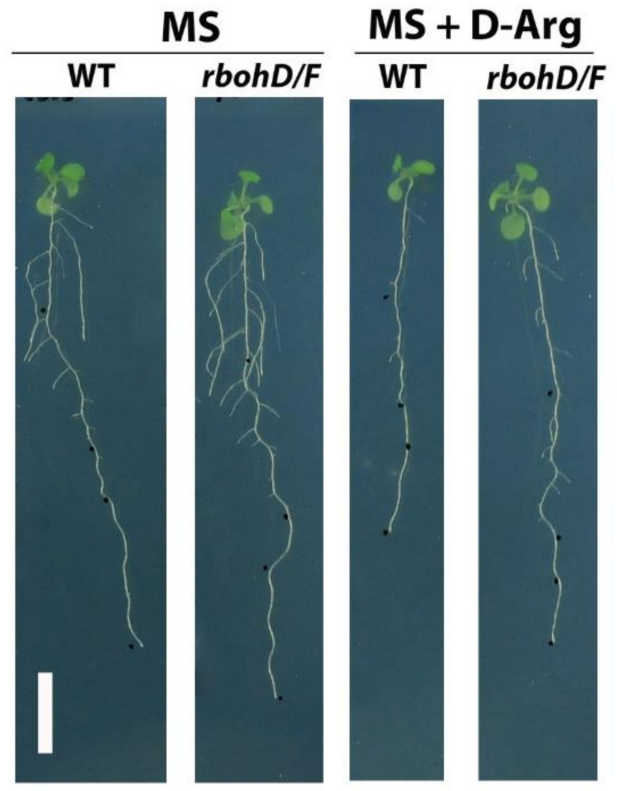

Figure 4. Effect of D-Arg treatment on WT and AtrbohD/F root growth indicates that $\mathrm{H}_{2} \mathrm{O}_{2}$ accumulation is not caused by NADPH oxidases. Five-day-old seedlings at the same developmental stage were transferred to new media containing water (Ctrl) or $0.8 \mathrm{mM}$ D-Arg and treated for 6 days. (A) New root growth length of WT and AtrbohD/F. (B) Seedling phenotype. Scale bar $=1 \mathrm{~cm}$. Data shown are averages \pm SD $(n>15)$.

\subsection{Auxin Response Exhibits a Non-Linear Trend as ADC1/2 Activity Decreases}

Auxin signaling promotes cell division and is involved in regulating root meristem size [47]. We analyzed the effects of Put depletion on the auxin response using the reporter line DR5::GFP. Interestingly, increasing levels of exogenous D-Arg had a non-linear effect on DR5-dependent GFP fluorescence (Figure 5A). We observed that $0.1 \mathrm{mM}$ D-Arg decreased DR5 activity by $15 \%$, but in contrast, higher D-Arg at 0.6 and $0.8 \mathrm{mM}$ significantly enhanced it by $20-25 \%$, respectively (Figure $5 \mathrm{~B}$ ). 
A

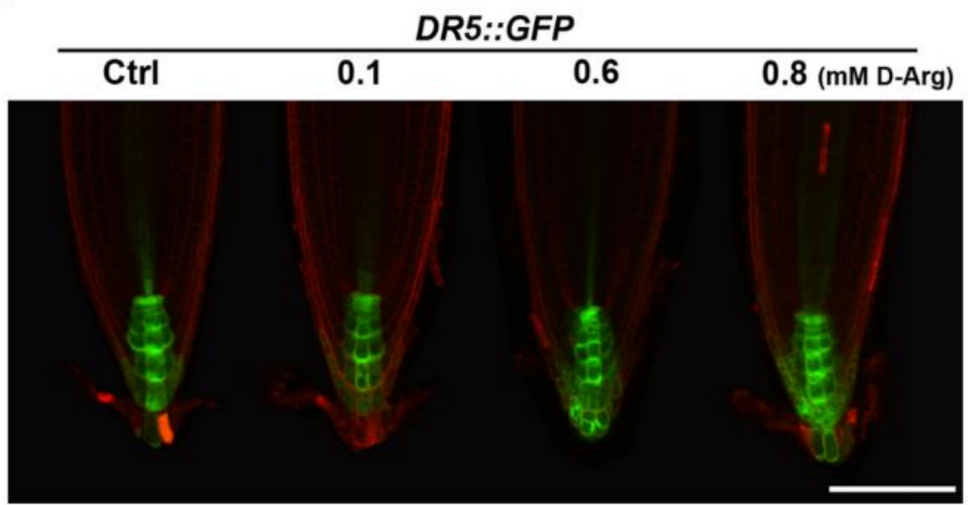

B

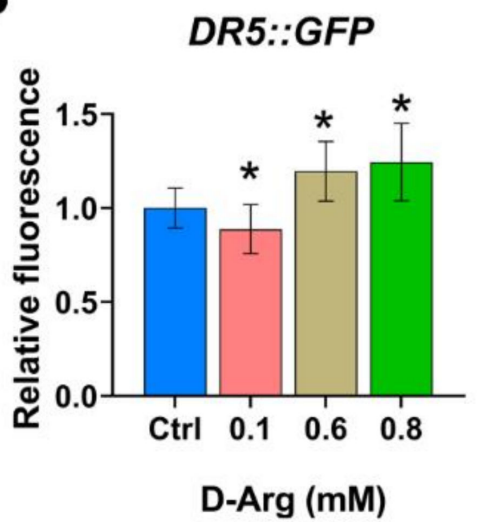

Figure 5. D-Arg treatment has a non-linear effect on auxin response. Five-day-old seedlings at the same developmental stage were transferred to new media containing water (Ctrl) or D-Arg and treated for 3 days. (A) Confocal images of DR5::GFP auxin response reporter. (B) DR5::GFP normalized fluorescence indicates a non-linear auxin response trend. Data are averages \pm SD $(n>15)$. Scale bar $=100 \mu \mathrm{m}$. Asterisks denote significant differences compared with the control ( $p<0.05$; Student's $t$-test).

\subsection{CK Response Gradually Decreases as D-Arg Increases}

Cytokinin (CK) signaling promotes cell differentiation and negatively regulates root meristem size [47]. To investigate whether reduced Put affects CK signaling, we used the reporter line proARR5::GFP. Arabidopsis response regulator 5 (ARR5) is a type-A negative regulator of cytokinin response and is strongly induced by CK [52]. Under different levels of D-Arg treatment, we observed that proARR5::GFP fluorescence gradually decreased (Figure $6 \mathrm{~A}$ ). The CK response was reduced significantly at $0.1 \mathrm{mM}$ D-Arg by $25 \%$ and at higher D-Arg levels of $0.6 \mathrm{mM}$ and $0.8 \mathrm{mM}$ by $33 \%$ to $35 \%$ compared to the untreated control (Figure 6B). ARR5 expression was measured using qRT-PCR at different concentrations of applied D-Arg. At low (0.01 mM) D-Arg, we observed a slight but not significant reduction in the ARR5 transcript level (Figure 6C). Similarly to the proARR5::GFP results, medium and high levels of D-Arg, at $0.1 \mathrm{mM}$ and $0.6 \mathrm{mM}$, significantly downregulated $A R R 5$ transcription by approximately $50 \%$, indicating that D-Arg treatment and Put depletion progressively reduces the CK response in the Arabidopsis root. Cytokinin activity is regulated by the balance between biosynthesis and degradation [53,54]. Cytokinin oxidase/dehydrogenases (CKXs) play a key role in CK degradation [54]. It has been reported that CKX family genes play critical roles in determining root architecture in several plant species [55-59]. In Arabidopsis, AtCKX1, AtCKX4, and AtCKX7 have been shown to either localize to the root or their overexpression has been shown to affect root phenotype $[53,56,60,61]$; however, this does not preclude other members of the CKX family playing a significant role in root development. Our results reveal that ADC1/2 inhibition significantly induced cytokinin oxidase1 (CKX1) expression levels and slightly induced $C K X 7$ in the root, whereas CKX4 was unchanged (Figure 6D). 
A

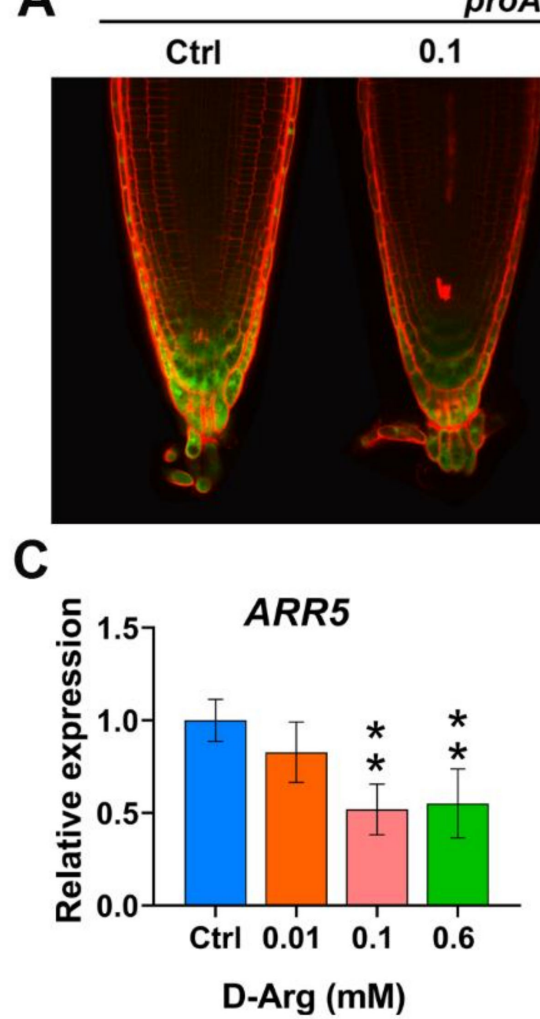

B

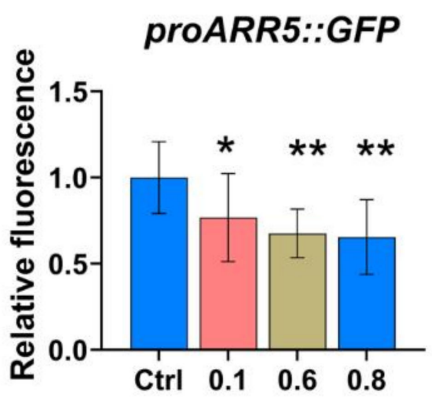

D-Arg (mM)

Figure 6. D-Arg treatment reduces the cytokinin response and increases CKX1 expression in the root meristem. Five-day-old seedlings at the same developmental stage were transferred to new media containing water (Ctrl) or D-Arg and treated for 3 days. (A,B) Confocal imaging indicates that increasing D-Arg gradually reduces cytokinin response proARR5::GFP and relative proARR5::GFP fluorescence. Scale bar $=100 \mu \mathrm{m}$. $(\mathbf{C}, \mathbf{D})$ qPCR data indicate that D-Arg treatment modulates the relative expression of $A R R 5$ and cytokinin oxidase $(C K X)$ genes. Data shown are averages $\pm \mathrm{SD}(\mathrm{n}>15)$. Asterisks indicate significant differences compared with the control $\left({ }^{*} p<0.05,{ }^{* *} p<0.01\right.$; Student's $t$-test).

\subsection{Differential Modulation of PIN1 and PIN2 Protein at Low and High D-Arg Treatment}

We explored the level of protein and localization of auxin efflux transporters PIN1 and PIN2 using two reporter lines, proPIN1::PIN1:GFP and proPIN2::PIN2:GFP. The auxin efflux transporter PIN1 is localized to the vascular tissue membrane of the root meristem and is involved in auxin transport from the stele to the quiescent center and columella initials [62]; PIN2 is localized mainly in the outer cell layers and is an essential component for basipetal auxin transport [63], and both PIN1 and PIN2 are important for correct auxin distribution [63]. Confocal imaging at low levels of D-Arg revealed significant increases in PIN1:GFP by $23 \%$ (Figure 7A,B) and PIN2:GFP by 35\% (Figure 7E,F) compared to untreated controls. At high D-Arg, the results showed that the level of PIN1:GFP was significantly increased by $30 \%$ compared to the untreated control (Figure 7C,D). In contrast, PIN2:GFP at the same D-Arg concentration was significantly decreased by $20 \%$ (Figure $7 \mathrm{G}, \mathrm{H}$ ). Our results therefore suggest that Put depletion alters PIN1 and PIN2 levels, cellular auxin efflux, and auxin distribution. 
A

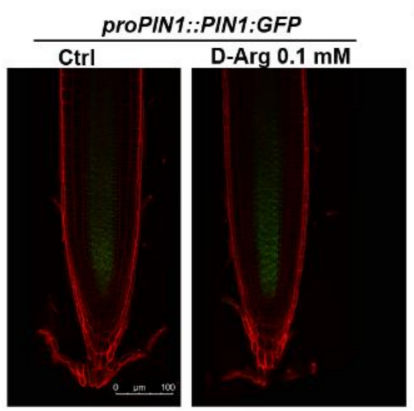

E

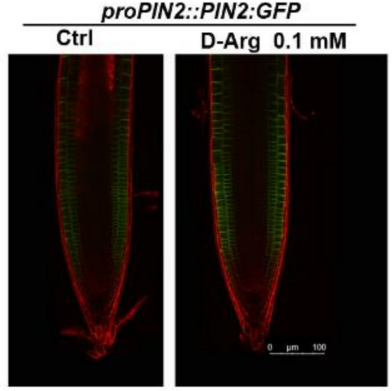

B

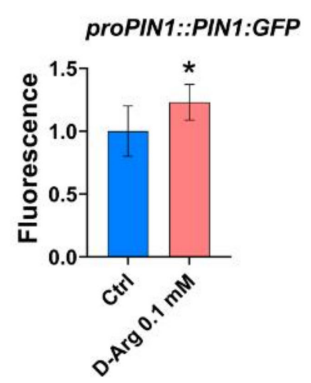

$\mathbf{F}$

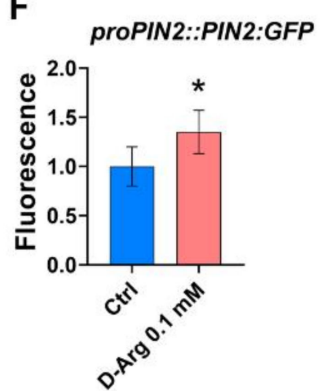

C

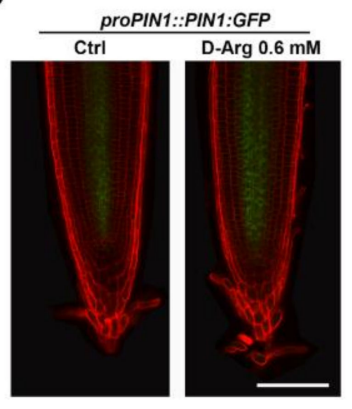

G

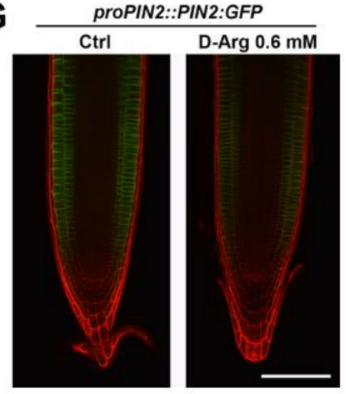

D

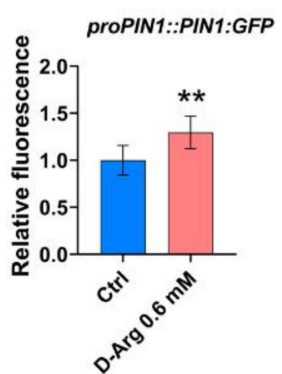

H

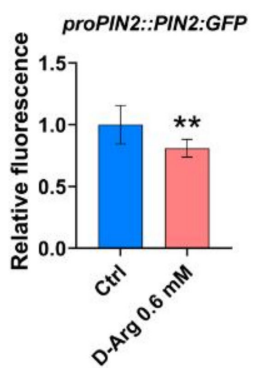

Figure 7. D-Arg treatment differentially affects PIN1 and PIN2 auxin efflux carriers. Five-day-old seedlings at the same developmental stage were transferred to new media containing water (Ctrl) or $0.6 \mathrm{mM} \mathrm{D}$-Arg and treated for 3 days. (A,B) Confocal imaging of proPIN1::PIN1:GFP reporter line and relative proPIN1::PIN1:GFP fluorescence indicate that low D-Arg treatment increases PIN1 protein. (C,D) proPIN1::PIN1:GFP reporter line and relative proPIN1::PIN1:GFP fluorescence indicate that high D-Arg treatment increases PIN1. (E,F) proPIN2::PIN2:GFP reporter line and relative proPIN2::PIN2:GFP fluorescence indicate that low D-Arg treatment increases PIN2 protein. (G,H) proPIN2::PIN2:GFP reporter line and relative proPIN2::PIN2:GFP fluorescence indicate that high D-Arg treatment reduces PIN2 protein. All scale bars $=100 \mu \mathrm{m}$. Data shown are averages $\pm \mathrm{SD}$ ( $n>15)$. Asterisks indicate significant differences compared with the control $\left({ }^{*} p<0.05,{ }^{* *} p<0.01\right.$; Student's $t$-test).

\section{Discussion}

The goal of our study was to investigate the effect of PAs on root growth and development in Arabidopsis and identify possible mechanisms by which PAs affect root phenotype under conditions of $\mathrm{ADC} 1 / 2$ inhibition. Under normal conditions, $A D C 1$ expression is localized to the shoot and $A D C 2$ expression to the root [64]. Our ADC2::GUS results (Figure 1D) confirm that $A D C 2$ expression is localized to the root. Given that neither adc1 or adc2 single mutants exhibited a root phenotype (Figure 1A), it is reasonable to assume that Put levels, directly or indirectly, affect the localization and/or level of $A D C 1 / 2$ expression. This assumption is supported by the literature, which provides evidence of $A D C 1 / 2$ regulation by both PAs and hormones [37,65-69]. To identify links between Put depletion and MZ size, we therefore used D-Arg application to simultaneously inhibit both $\mathrm{ADC} 1$ and $\mathrm{ADC} 2$ to ensure a reduction in Put levels, rather than developing specific $A D C 2$ knockdowns. Although $A D C 1 / 2$ regulation, localization, or redundancy are important components of this complex biological system, it was not part of this initial study but could be addressed in future research.

PA levels were modified by using the specific ADC1/2 enzyme inhibitor D-Arg to perturb PA biosynthesis instead of using PA treatment, since exogenous application, for example of Spd, could artificially increase Spd levels, affect PA balance, and generate ROS due to reverse biosynthesis and terminal catabolism $[8,28,29]$. D-Arg application has been used to deplete Put in several research papers [41-46]; however, none of these papers addressed the issue of whether D-Arg application could produce any significant additional effects by, for instance, regulation of other enzyme activities or by increasing the availability of the ADC1/2 substrate, L-Arg. This is an outstanding issue for future research, which is discussed further in the conclusion. 
Inhibition of ADC1/2 reduced Put levels and resulted in unpredictable changes in the levels of higher PAs. As Put levels decreased, Spd remained stable until high D-Arg application, when levels dropped significantly, and Spm + Tspm levels initially increased and then decreased at high D-Arg. These unexpected and differing trends in PA levels under conditions of progressive ADC1/2 inhibition demonstrate the complexity of the PA forward and reverse biosynthesis pathways that re-balance PA levels when Put is depleted. A more detailed examination of how PA levels change under different conditions of enzyme inhibition, PA treatment, or under stress conditions could prove useful in investigating the regulation of PA balancing.

Put depletion resulted in non-intuitive phenotype outcomes, with increased MZ size observed at low levels of D-Arg application and progressively decreasing MZ size at higher $D-A r g$. This inverted-U trend in MZ size suggests that more than one mechanism regulates MZ size: for example, with one mechanism promoting MZ size at low D-Arg concentrations and another antagonistic mechanism inhibiting MZ size at higher D-Arg levels. At low D-Arg levels the first mechanism acts to increase MZ size, but as D-Arg treatment increases, the second mechanism becomes dominant in order to reduce MZ size.

It has been shown that root MZ size is determined by the balance between cell division and differentiation and that this process is regulated by two mechanisms-auxin and CK signaling balance [47], and changes in ROS homeostasis [34] that are independent of auxin and CK signaling. We therefore examined these two candidate mechanisms. Since auxin promotes cell division, whereas $\mathrm{CK}$ promotes differentiation, the auxin-to-CK signaling balance modulates MZ size [47], rather than individual auxin or CK signaling trends. Auxin signaling displayed a U-shaped trend as D-Arg increased, whereas cytokinin progressively decreased. At low D-Arg application, no change in ROS accumulation was observed, but the auxin:CK ratio shifted in favor of auxin to enlarge the $\mathrm{MZ}$, consistent with the literature [47]. However, at higher D-Arg levels, we observed increasing ROS accumulation, which is known to inhibit MZ size [34,70-72]. The results for DAB and NBT staining (Figure 3D) suggest that high Put depletion led to the accumulation of $\mathrm{H}_{2} \mathrm{O}_{2}$ but not of $\mathrm{O}_{2}{ }^{-}$and that that $\mathrm{H}_{2} \mathrm{O}_{2}$ accumulation is caused by PAO activity, rather than by NADPH oxidases (Figure 4). The ROS effect was confirmed with phenotype rescue by ROS scavenging using KI; however, the partial rescue at high D-Arg also suggests that additional mechanism(s) could be involved in $\mathrm{MZ}$ size and root growth regulation.

We concluded that the hormone effect promoted MZ size at low D-Arg but that at higher D-Arg the antagonistic ROS effect dominated to reduce the MZ. The underlying mechanisms whereby Put depletion modulates ROS accumulation and auxin and cytokinin signaling have yet to be unraveled; however, the literature points to several promising lines of investigation: (1) previous studies report that PAs play two opposing roles in the regulation of ROS levels as both ROS scavengers under stress [32,33] and as a source of ROS generated by terminal and back conversion pathways [8,28,29], (2) Spd and Spm have been shown to regulate CKX [37,38,73] and auxin conjugation [37], and (3) Tspm inhibits the final steps in the CK biosynthesis pathway [3,74].

The results of our work indicate that Put depletion affects root phenotype through the antagonistic actions of hormone signaling and ROS accumulation; however, the question remains as to whether this is due to direct or indirect effects of changing Put levels. As noted earlier, PA levels are closely linked by forward and reverse biosynthesis pathways. Furthermore, terminal catabolism of excess PAs and back-conversion to lower-level PAs can produce bioactive products. These mechanisms constitute an extremely complex process by which perturbation of a single PA can result in changes in other PAs and in the generation of bioactive products. This is in part illustrated by our HPLC experiments, which produced non-intuitive results in regard to the changes in higher PAs when Put was depleted. It is therefore likely that perturbation of any single PA results in PA re-balancing and effects phenotype outcomes by multiple direct and indirect pathways. Several studies also indicate that the overall PA balance seems to be more important than the specific effect of individual PAs $[15,75]$. 
Previous work [47] showed that changes in relative auxin to CK signaling modulate $\mathrm{MZ}$ size through the regulation of auxin transporters and modified auxin distribution. In our work, at low D-Arg the proPIN1::PIN1:GFP protein reporter showed an increase in PIN1 and the proPIN2::PIN2:GFP showed an increase in PIN2, whereas upon high DArg treatment, PIN1 increased and PIN2 decreased (Figure 7), indicating that ADC1/2 inhibition differentially modulates PIN1 and PIN2 protein levels to modify auxin transport and distribution.

The above data demonstrate that hormone signaling and ROS accumulation are two mechanisms by which PAs regulate MZ size (Figure 8).

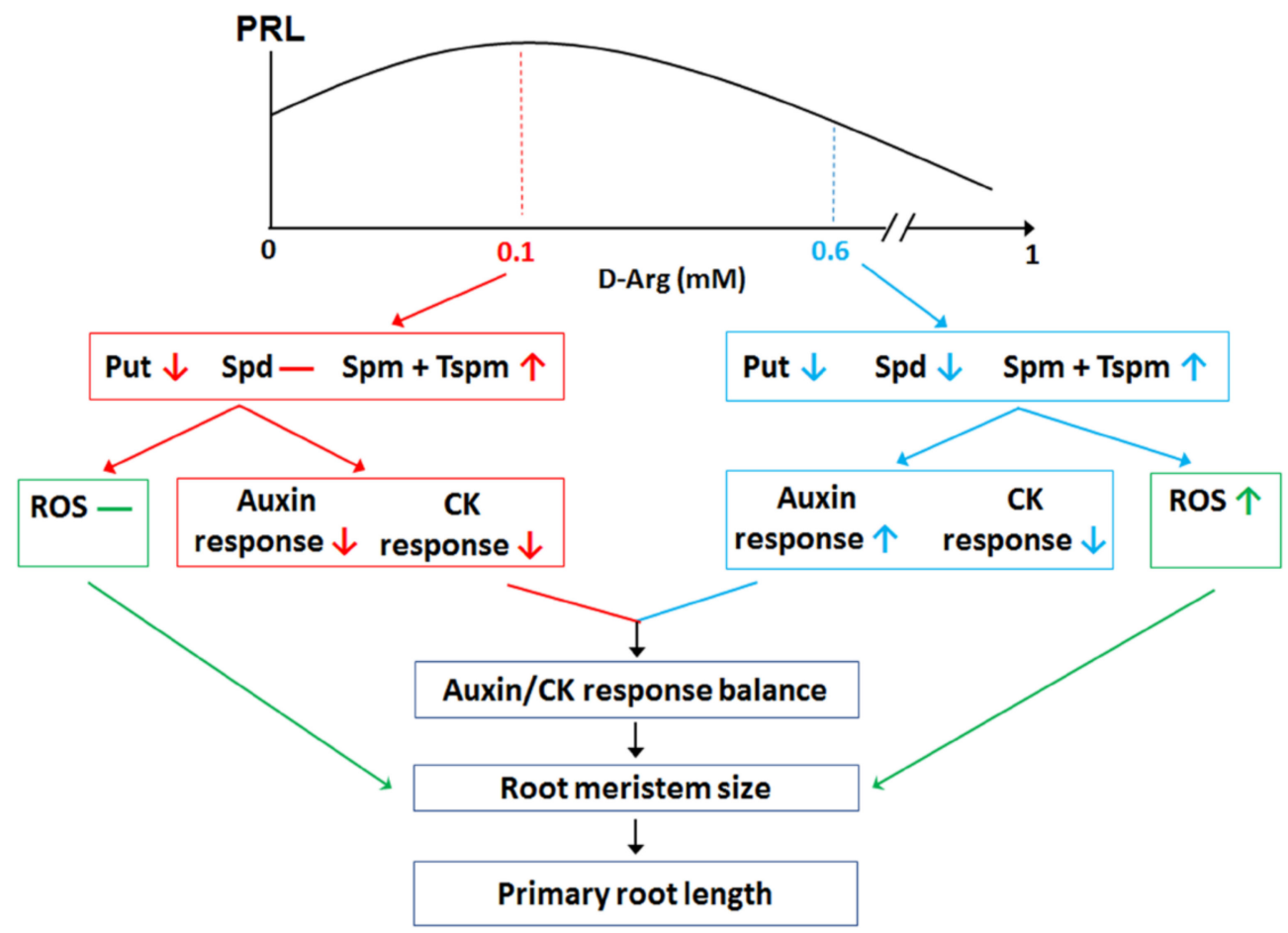

Figure 8. ADC1/2 inhibition differentially changes PA levels and has a non-linear effect on meristem size by modulating relative auxin/CK signaling and ROS accumulation. Exogenous application of increasing D-Arg concentrations differentially modified Put, Spd, and Spm + Tspm levels and resulted in an inverted-U trend in primary root growth. Medium D-Arg at $0.1 \mathrm{mM}$ (red boxes) promoted root growth, decreased the auxin and CK response, and had no effect on ROS levels (green boxes). High D-Arg $0.6 \mathrm{mM}$ (blue boxes) reduced root growth, differentially affected auxin and CK response, and accumulated ROS. PRL, primary root length. Vertical arrows denote a statistically significant increase $\uparrow$ or decrease $\downarrow$, whereas a horizontal line indicates no significant change.

\section{Materials and Methods}

\subsection{Plant Materials and Growth Conditions}

All experiments were performed using Arabidopsis thaliana ecotype Columbia (Col$0)$. Transgenic marker lines are in Col-0 backgrounds as follows: DR5::GFP for auxinresponse; proPIN1::PIN1:GFP and proPIN2::PIN2:GFP for PIN1/2 auxin efflux carrier proteins; proARR5::GFP for cytokinin response; and proADC2::GUS for localization of ADC2 expression. Genetic materials, T-DNA insertion mutant adc1 and adc2 for polyamine biosynthesis pathway and atrbohD/F for ROS experiments were used.

Seeds were surfaced-sterilized for $2 \mathrm{~min}$ in $75 \%$ ethanol and then $10 \mathrm{~min}$ in $1 \%$ sodium hypochlorite. Seeds were washed five times with sterilized deionized water. For simultaneous germination, all seeds were stratified for $2-3$ days at $4{ }^{\circ} \mathrm{C}$ before germination.

Seeds were grown on $120 \times 120 \times 17 \mathrm{~mm}$ square plates containing half-strength Murashige and Skoog (MS) medium $2.2 \mathrm{~g} \mathrm{~L}^{-1}$ (Duchefa Biochemie) including vitamins, MES $0.5 \mathrm{~g} \mathrm{~L}^{-1}$ (Duchefa Biochemie), and 1\% (w/v) sucrose and solidified with 1\% agar 
(Duchefa Biochemie). PH was adjusted to 5.8 with $\mathrm{KOH}$. Plated were sealed with Micropore tape.

To maintain the root for molecular assay and physical root measurements, seedlings were grown and placed vertically in the growth incubator at $22{ }^{\circ} \mathrm{C}$ with light cycles of $16 \mathrm{~h}$ light $/ 8 \mathrm{~h}$ dark (light intensity: $\sim 120 \mu \mathrm{mol} / \mathrm{s} / \mathrm{m}^{2}$, and relative humidity of $60 \%$ ). For putrescine depletion, 5-day-old seedlings were transferred to MS medium containing 0 , $0.01,0.05,0.1,0.3,0.6,0.8$, and $1 \mathrm{mM}$ of D-Arginine (Sangon Biotech, Shanghai, China) for a further 3 days. For experiments involving double atrbohD/F loss-of-function mutants, the D-Arg treatment period was extended from 3 to 6 days and new root growth length was observed to ensure that NADPH oxidases were not a significant source of ROS accumulation under conditions of Put depletion.

\subsection{Root Length, Root Meristem Size, and Cell Length Measurements}

To track changes in root growth, five-day-old seedlings with the same root length were transferred to a fresh medium containing either water as control or D-Arginine. The position of the root tip was marked on the back of plates at the time of transfer and new root growth length was measured as root growth extension during the treatment period, using images taken with a Nikon D300s digital camera (Nikon Corp., Tokyo, Japan).

For root meristem measurements, after 3 days D-Arg treatment seedlings were cleared with chloral hydrate solution [76]. Root meristem size was determined as the length from the quiescent center $(\mathrm{QC})$ to where the cell was double the size of the previous cell along the cortex cell layer $[77,78]$. Root meristems were analyzed and imaged using an Olympus BX61 microscope (Olympus, Tokyo, Japan) equipped with differential interference contrast (DIC) optics, 20x UPlanSApo objective, and a CCD camera (Olympus DP74). For Photo acquisition, Olympus cellSens software was used.

\subsection{Confocal Laser Scanning Microscopy}

All confocal root images were taken with a Leica SP8 confocal laser scanning microscope (https:/ /www.leica-microsystems.com) after three days of D-Arg treatment. Ten micrograms per milliliter of propidium iodide (PI) solution (Sangon Biotech, Shanghai, China) were used to visualize cell walls. Stained roots were visualized with the excitation wavelength set at $548 \mathrm{~nm}$ for PI and at $488 \mathrm{~nm}$ for green fluorescent protein (GFP).

\subsection{RNA Extraction, $c D N A$ Synthesis, and $q R T-P C R$}

Whole roots of Col-0 wild type non-treated (Ctrl) and treated with D-Arginine (D-Arg) were used. Total RNA extraction was performed using TransZol Up reagent (TransGen, Beijing, China). RNA concentration and quality were determined with a Nanodrop 2000 Spectrophotometer (Thermo Fisher Scientific). cDNA was synthesized from $1 \mu \mathrm{g}$ of RNA using a TransScript One-Step gDNA Removal and cDNA Synthesis SuperMix kit (TransGen, Beijing, China), following the manufacturer's instructions. cDNA was diluted 1:10 for quantitative real-time PCR (qPCR).

Quantitative real-time PCR analyses were performed using TransStart Tip Green qPCR SuperMix (TransGen, Beijing, China) with a Roche LightCycler 480 thermal cycler instrument, 384-well (Roche). Relative expression values were calculated using the $2^{-\Delta \Delta \mathrm{Ct}}$ method [79], and ACTIN2 was used as a reference gene. Primers are listed in Table S1. Three biological replicates were performed for each sample and each biological replicate was represented by three technical replicates.

\subsection{Quantification of Free Polyamine}

Free PA quantification was performed using high-performance liquid chromatography (HPLC). Five-day-old seedlings at the same developmental stage were selected and transferred to the treatment media containing D-Arg for another 3 days. Zero point three five grams of fresh weight of seedlings were harvested for analysis. The extraction and 
quantification methods were performed as described in [80]. 1,6-hexanediamine was used as an internal standard.

\subsection{Histochemical GUS Staining}

Transgenic Arabidopsis containing ADC2 promoter::GUS fusions were stained for GUS according to the method described in [32].

\subsection{Determination of $\mathrm{O}_{2}{ }^{-}$and $\mathrm{H}_{2} \mathrm{O}_{2}$ by NBT and DAB Staining}

3,3'-Diaminobenzidine (DAB, $1 \mathrm{mg} \mathrm{mL}^{-1}$ ) staining (Sigma Aldrich) was used to detect $\mathrm{H}_{2} \mathrm{O}_{2}$ levels in roots, and Nitrotetrazolium blue (NBT, $1 \mathrm{mg} \mathrm{mL}^{-1}$ ) (Sangon Biotech, Shanghai, China) was used for $\mathrm{O}_{2}{ }^{-}$detection. DAB and NBT staining were performed as described by [32]. At least 30 root meristems for each staining were analyzed and imaged using an Olympus BX61 microscope (Olympus, Tokyo, Japan) equipped with differential interference contrast (DIC) optics, $20 \times$ UPlanSApo objective, and a CCD camera (Olympus DP74). For photo acquisition, Olympus cellSens software was used.

\subsection{Image Analysis}

Root length, meristem size, cell counts, DAB, and NBT images were investigated using ImageJ (http:/ / www.imagej.nih.gov/ij/). DAB, and NBT stained images were quantified as described in [32]. Mean relative fluorescence for confocal images was calculated with ImageJ. In quantifying fluorescence, at least 15 seedlings per line were used.

\subsection{Statistical Analysis}

All experiments were performed at least three times. For statistical comparisons, we used Student's $t$-test. Data shown are averages \pm SD. Asterisks indicate significant differences compared with the control $\left(^{*}, p<0.05,{ }^{* *}, p<0.01,{ }^{* * *}, p<0.001\right)$.

\section{Conclusions}

In this study, we investigated the effect of PAs on root development in Arabidopsis with the goal of identifying mechanisms by which PAs affect root growth. We explored changes in ROS accumulation and hormone signaling under conditions of ADC1/2 inhibition and Put depletion, and the results demonstrated that the effects of PAs on root phenotype are mediated by ROS and hormone signaling. Furthermore, the data generated by this study indicate that PA regulation of root phenotype is extremely complex, involving (1) intricate forward and reverse PA biosynthesis, (2) changes in ROS accumulation generated by PA catabolism and reverse biosynthesis and potentially by PA-mediated $\mathrm{H}_{2} \mathrm{O}_{2}$ scavenging, and (3) the complexities of hormonal crosstalk, resulting in a modified auxin distribution and $\mathrm{CK}$ response and changes to the ratio of auxin to $\mathrm{CK}$ signaling. This complexity is further evidenced by the contrasting changes in PA levels observed as ADC1/2 inhibition increased; by the non-linear trends in root growth, MZ size, and auxin response; and also by the differential regulation of PIN1 and PIN2 transporters.

Having identified candidate mechanisms linking PAs to root phenotype, future work requires more detailed investigations of these pathways under conditions of Put depletion. As noted earlier, although D-Arg treatment has been used in several studies to reduce Put, questions remain about the possible side-effects of D-Arg treatment. Therefore, the first step in future research will be to address this issue by developing ADC1/2 knockdowns and making comparisons with D-Arg treatment results for gene expression, hormone signaling, ROS accumulation, and phenotype. It would be ideal to be able to calibrate each knockdown with a specific D-Arg treatment level and, provided there is no significant difference between results for the knockdowns and D-Arg application, the two methods can be combined to deplete Put, utilizing the convenience of D-Arg that also allows finetuning of Put levels, which is difficult to achieve with knockdowns alone. The next step is to investigate mechanisms by which PAs modulate hormone signaling. The literature suggests links between PAs and auxin conjugation [37], CK biosynthesis [3,74], and CK 
degradation $[37,38]$, and therefore the initial focus should be on components of these signaling pathways using genetic material. During this phase, possible ROS effects will be removed through the application of KI. A similar approach can be adopted for analyzing links between PAs and ROS.

Our initial results and the literature indicate that PA levels are closely inter-related and that it is difficult to predict how the perturbation of one PA will affect other PAs, hormone signaling, ROS accumulation, and phenotype. Therefore, another interesting research area would be a more detailed examination of PA balancing and downstream effects by treating WT and $a d c 1$ and $a d c 2$ single mutants and knockdowns with D-Arg and PAs, and observing them under stress conditions. Since ADC1/2 enzymes appear to have some level of redundancy given that single mutants do not exhibit phenotypes, the investigation of enzyme expression, localization, and redundancy under different conditions could also be carried out.

Supplementary Materials: Supplementary Materials can be found at https://www.mdpi.com/ article/10.3390/ijms22084094/s1.

Author Contributions: A.M.H., S.C., C.H., Q.Z., I.E.E. and Y.F. performed the experiments with support from S.M. and J.F.T., J.L., and K.L. C.C. conceived the project. C.C. and A.M.H. designed the experiments. A.M.H., S.M., and C.C. analyzed the data and wrote the manuscript. All authors read and approved of this content. All authors have read and agreed to the published version of the manuscript.

Funding: This research was supported by the National Natural Science Foundation of China (No.31971520), Advanced Foreign Experts Project (G20200017071, G20190017014), and Fundamental Research Funds for the Central Universities (2662018PY099) from the Chinese government.

Institutional Review Board Statement: Not applicable.

Informed Consent Statement: Not applicable.

Data Availability Statement: Not applicable.

Conflicts of Interest: The authors declare no conflict of interest.

$\begin{array}{ll}\text { Abbreviations } \\ \text { PAs } & \text { Polyamines } \\ \text { ADC } & \text { Arginine decarboxylase } \\ \text { CK } & \text { Cytokinin } \\ \text { MZ } & \text { Meristem zone } \\ \text { Put } & \text { Putrescine } \\ \text { Spd } & \text { Spermidine } \\ \text { Spm } & \text { Spermine } \\ \text { Tspm } & \text { Thermospermine } \\ \text { uORFs } & \text { Upstream open reading frames } \\ \text { D-Arg } & \text { D-Arginine } \\ \text { CuAOs } & \text { Copper-containing amine oxidases } \\ \text { PAOs } & \text { Polyamine oxidase } \\ \text { RBOH } & \text { Respiratory burst oxidase homolog } \\ \text { ROS } & \text { Reactive oxygen species } \\ \text { CKX } & \text { Cytokinin oxidase } \\ \text { ARR } & \text { Arabidopsis response regulator } \\ \text { QC } & \text { Quiescent center }\end{array}$

\section{References}

1. Igarashi, K.; Kashiwagi, K. Modulation of cellular function by polyamines. Int. J. Biochem. Cell Biol. 2010, 42, 39-51. [CrossRef] [PubMed]

2. Imai, A.; Matsuyama, T.; Hanzawa, Y.; Akiyama, T.; Tamaoki, M.; Saji, H.; Shirano, Y.; Kato, T.; Hayashi, H.; Shibata, D.; et al. Spermidine synthase genes are essential for survival of Arabidopsis. Plant Physiol. 2004, 135, 1565-1573. [CrossRef] [PubMed] 
3. Takano, A.; Kakehi, J.I.; Takahashi, T. Thermospermine is not a minor polyamine in the plant kingdom. Plant Cell Physiol. 2012, 53, 606-616. [CrossRef] [PubMed]

4. Chen, D.; Shao, Q.; Yin, L.; Younis, A.; Zheng, B. Polyamine function in plants: Metabolism, regulation on development, and roles in abiotic stress responses. Front. Plant Sci. 2018, 9, 1945. [CrossRef]

5. Zhang, Y.; Wu, R.; Qin, G.; Chen, Z.; Gu, H.; Qu, L.J. Over-expression of WOX1 leads to defects in meristem development and polyamine homeostasis in arabidopsisf. J. Integr. Plant Biol. 2011, 53, 493-506. [CrossRef]

6. Alcázar, R.; Altabella, T.; Marco, F.; Bortolotti, C.; Reymond, M.; Koncz, C.; Carrasco, P.; Tiburcio, A.F. Polyamines: Molecules with regulatory functions in plant abiotic stress tolerance. Planta 2010, 231, 1237-1249. [CrossRef]

7. Shi, H.; Chan, Z. Improvement of plant abiotic stress tolerance through modulation of the polyamine pathway. J. Integr. Plant Biol. 2014, 56, 114-121. [CrossRef]

8. Tiburcio, A.F.; Altabella, T.; Bitrián, M.; Alcázar, R. The roles of polyamines during the lifespan of plants: From development to stress. Planta 2014, 240, 1-18. [CrossRef]

9. Takahashi, T. Plant Polyamines. Plants 2020, 9, 511. [CrossRef]

10. Hanfrey, C.; Sommer, S.; Mayer, M.J.; Burtin, D.; Michael, A.J. Arabidopsis polyamine biosynthesis: Absence of ornithine decarboxylase and the mechanism of arginine decarboxylase activity. Plant J. 2001, 27, 551-560. [CrossRef]

11. Lou, Y.-R.; Ahmed, S.; Yan, J.; Adio, A.M.; Powell, H.M.; Morris, P.F.; Jander, G. Arabidopsis ADC1 functions as an N $\delta$ acetylornithine decarboxylase. J. Integr. Plant Biol. 2020, 62, 601-613. [CrossRef]

12. Chang, K.S.; Lee, S.H.; Hwang, S.B.; Park, K.Y. Characterization and translational regulation of the arginine decarboxylase gene in carnation (Dianthus caryophyllus L.). Plant J. 2000, 24, 45-56. [CrossRef]

13. Baron, K.; Stasolla, C. The role of polyamines during in vivo and in vitro development. Vitr. Cell. Dev. Biol. Plant 2008, 44, 384-395. [CrossRef]

14. Guerrero-González, M.L.; Rodríguez-Kessler, M.; Jiménez-Bremont, J.F. uORF, a regulatory mechanism of the Arabidopsis polyamine oxidase 2. Mol. Biol. Rep. 2014, 41, 2427-2443. [CrossRef]

15. Hummel, I.; Couée, I.; El Amrani, A.; Martin-Tanguy, J.; Hennion, F. Involvement of polyamines in root development at low temperature in the subantarctic cruciferous species Pringlea antiscorbutica. J. Exp. Bot. 2002, 53, 1463-1473. [CrossRef]

16. Urano, K.; Yoshiba, Y.; Nanjo, T.; Ito, T.; Yamaguchi-Shinozaki, K.; Shinozaki, K. Arabidopsis stress-inducible gene for arginine decarboxylase AtADC2 is required for accumulation of putrescine in salt tolerance. Biochem. Biophys. Res. Commun. 2004, 313, 369-375. [CrossRef]

17. Alcázar, R.; García-Martínez, J.L.; Cuevas, J.C.; Tiburcio, A.F.; Altabella, T. Overexpression of ADC2 in Arabidopsis induces dwarfism and late-flowering through GA deficiency. Plant J. 2005, 43, 425-436. [CrossRef]

18. Sánchez-Rangel, D.; Chávez-Martínez, A.I.; Rodríguez-Hernández, A.A.; Maruri-López, I.; Urano, K.; Shinozaki, K.; JiménezBremont, J.F. Simultaneous Silencing of two arginine decarboxylase genes alters development in Arabidopsis. Front. Plant Sci. 2016, 7, 300. [CrossRef]

19. Bhatnagar, P.; Minocha, R.; Minocha, S.C. Genetic manipulation of the metabolism of polyamines in poplar cells. The regulation of putrescine catabolism. Plant Physiol. 2002, 128, 1455-1469. [CrossRef]

20. Urano, K.; Hobo, T.; Shinozaki, K. Arabidopsis ADC genes involved in polyamine biosynthesis areb essential for seed development. FEBS Lett. 2005, 579, 1557-1564. [CrossRef]

21. Cui, X.; Ge, C.; Wang, R.; Wang, H.; Chen, W.; Fu, Z.; Jiang, X.; Li, J.; Wang, Y. The BUD2 mutation affects plant architecture through altering cytokinin and auxin responses in Arabidopsis. Cell Res. 2010, 20, 576-586. [CrossRef] [PubMed]

22. Mirza, J.I.; Bagni, N. Effects of exogenous polyamines and difluoromethylornithine on seed germination and root growth of Arabidopsis thaliana. Plant Growth Regul. 1991, 10, 163-168. [CrossRef]

23. Ghuge, S.A.; Carucci, A.; Rodrigues-Pousada, R.A.; Tisi, A.; Franchi, S.; Tavladoraki, P.; Angelini, R.; Cona, A. The apoplastic copper AMINE OXIDASE1 mediates jasmonic acid-induced protoxylem differentiation in Arabidopsis roots. Plant Physiol. 2015, 168, 690-707. [CrossRef] [PubMed]

24. Fraudentali, I.; Rodrigues-Pousada, R.A.; Tavladoraki, P.; Angelini, R.; Cona, A. Leaf-wounding long-distance signaling targets AtCuAO $\beta$ leading to root phenotypic plasticity. Plants 2020, 9, 249. [CrossRef]

25. Tarenghi, E.; Carré, M.; Martin-Tanguy, J. Effects of inhibitors of polyamine biosynthesis and of polyamines on strawberry microcutting growth and development. Plant Cell. Tissue Organ Cult. 1995, 42, 47-55. [CrossRef]

26. Yoshimoto, K.; Takamura, H.; Kadota, I.; Motose, H.; Takahashi, T. Chemical control of xylem differentiation by thermospermine, xylemin, and auxin. Sci. Rep. 2016, 6, 21487. [CrossRef]

27. Alabdallah, O.; Ahou, A.; Mancuso, N.; Pompili, V.; Macone, A.; Pashkoulov, D.; Stano, P.; Cona, A.; Angelini, R.; Tavladoraki, P. The Arabidopsis polyamine oxidase/dehydrogenase 5 interferes with cytokinin and auxin signaling pathways to control xylem differentiation. J. Exp. Bot. 2017, 68, 997-1012. [CrossRef]

28. Cona, A.; Rea, G.; Angelini, R.; Federico, R.; Tavladoraki, P. Functions of amine oxidases in plant development and defence. Trends Plant Sci. 2006, 11, 80-88. [CrossRef]

29. Angelini, R.; Cona, A.; Federico, R.; Fincato, P.; Tavladoraki, P.; Tisi, A. Plant amine oxidases "on the move": An update. Plant Physiol. Biochem. PPB 2010, 48, 560-564. [CrossRef]

30. Corpas, F.J.; del Río, L.A.; Palma, J.M. Plant peroxisomes at the crossroad of NO and H2O2 metabolism. J. Integr. Plant Biol. 2019, 61, 803-816. [CrossRef] 
31. Takahashi, T.; Kakehi, J.I. Polyamines: Ubiquitous polycations with unique roles in growth and stress responses. Ann. Bot. 2010, 105, 1-6. [CrossRef]

32. Fu, Y.; Guo, C.; Wu, H.; Chen, C. Arginine decarboxylase ADC2 enhances salt tolerance through increasing ROS scavenging enzyme activity in Arabidopsis thaliana. Plant Growth Regul. 2017, 83, 253-263. [CrossRef]

33. López-Gómez, M.; Hidalgo-Castellanos, J.; Muñoz-Sánchez, J.R.; Marín-Peña, A.J.; Lluch, C.; Herrera-Cervera, J.A. Polyamines contribute to salinity tolerance in the symbiosis Medicago truncatula-Sinorhizobium meliloti by preventing oxidative damage. Plant Physiol. Biochem. 2017, 116, 9-17. [CrossRef]

34. Tsukagoshi, H.; Busch, W.; Benfey, P.N. Transcriptional Regulation of ROS Controls Transition from Proliferation to Differentiation in the root. Cell 2010, 143, 606-616. [CrossRef]

35. Tisi, A.; Federico, R.; Moreno, S.; Lucretti, S.; Moschou, P.N.; Roubelakis-Angelakis, K.A.; Angelini, R.; Cona, A. Perturbation of polyamine catabolism can strongly affect root development and xylem differentiation. Plant Physiol. 2011, 157, 200-215. [CrossRef]

36. Bitrián, M.; Zarza, X.; Altabella, T.; Tiburcio, A.F.; Alcázar, R. Polyamines under abiotic stress: Metabolic crossroads and hormonal crosstalks in plants. Metabolites 2012, 2, 516-528. [CrossRef]

37. Anwar, R.; Mattoo, A.K.; Handa, A.K. Polyamine interactions with plant hormones: Crosstalk at several levels. In Polyamines: A Universal Molecular Nexus for Growth, Survival, and Specialized Metabolism; Springer: Tokyo, Japan, 2015; pp. $267-302$.

38. Marco, F.; Alcázar, R.; Tiburcio, A.F.; Carrasco, P. Interactions between polyamines and abiotic stress pathway responses unraveled by transcriptome analysis of polyamine overproducers. OMICS 2011, 15, 775-781. [CrossRef]

39. Mendes, A.F.S.; Cidade, L.C.; Otoni, W.C.; Soares-Filho, W.S.; Costa, M.G.C. Role of auxins, polyamines and ethylene in root formation and growth in sweet orange. Biol. Plant. 2011, 55, 375. [CrossRef]

40. Saini, S.; Sharma, I.; Kaur, N.; Pati, P.K. Auxin: A master regulator in plant root development. Plant Cell Rep. 2013, 32, 741-757. [CrossRef]

41. Roberts, D.R.; Walker, M.A.; Thompson, J.E.; Dumbroff, E.B. The Effects of inhibitors of polyamine and ethylene biosynthesis on senescence, ethylene production and polyamine levels in cut carnation flowers. Plant Cell Physiol. 1984, 25, 315-322. [CrossRef]

42. Tiburcio, A.F.; Kaur-Sawhney, R.; Galston, A.W. Effect of polyamine biosynthetic inhibitors on alkaloids and organogenesis in tobacco callus cultures. Plant Cell. Tissue Organ Cult. 1987, 9, 111-120. [CrossRef] [PubMed]

43. Liu, J.-H.; Nada, K.; Honda, C.; Kitashiba, H.; Wen, X.-P.; Pang, X.-M.; Moriguchi, T. Polyamine biosynthesis of apple callus under salt stress: Importance of the arginine decarboxylase pathway in stress response. J. Exp. Bot. 2006, 57, 2589-2599. [CrossRef] [PubMed]

44. Wang, J.; Sun, P.P.; Chen, C.L.; Wang, Y.; Fu, X.Z.; Liu, J.H. An arginine decarboxylase gene PtADC from Poncirus trifoliata confers abiotic stress tolerance and promotes primary root growth in Arabidopsis. J. Exp. Bot. 2011, 62, 2899-2914. [CrossRef] [PubMed]

45. Wu, H.; Fu, B.; Sun, P.; Xiao, C.; Liu, J.H. A NAC transcription factor represses putrescine biosynthesis and affects drought tolerance. Plant Physiol. 2016, 172, 1532-1547. [CrossRef]

46. Gao, C.; Sheteiwy, M.S.; Han, J.; Dong, Z.; Pan, R.; Guan, Y.; Hamoud, Y.A.; Hu, J. Polyamine biosynthetic pathways and their relation with the cold tolerance of maize (Zea mays L.) seedlings. Plant Signal. Behav. 2020, 15, 7722. [CrossRef]

47. Dello Ioio, R.; Nakamura, K.; Moubayidin, L.; Perilli, S.; Taniguchi, M.; Morita, M.T.; Aoyama, T.; Costantino, P.; Sabatini, S. A genetic framework for the control of cell division and differentiation in the root meristem. Science 2008, 322, 1380-1384. [CrossRef]

48. Daudi, A.; Cheng, Z.; O’Brien, J.A.; Mammarella, N.; Khan, S.; Ausubel, F.M.; Bolwell, G.P. The Apoplastic Oxidative Burst Peroxidase in Arabidopsis is a Major Component of Pattern-Triggered Immunity. Plant Cell 2012, 24, 275-287. [CrossRef]

49. Kadota, Y.; Shirasu, K.; Zipfel, C. Regulation of the NADPH oxidase RBOHD during plant immunity. Plant Cell Physiol. 2015, 56, 1472-1480. [CrossRef]

50. Gémes, K.; Kim, Y.J.; Park, K.Y.; Moschou, P.N.; Andronis, E.; Valassaki, C.; Roussis, A.; Roubelakis-Angelakis, K.A. An NADPH-oxidase/polyamine oxidase feedback loop controls oxidative burst under salinity. Plant Physiol. 2016, 172, 1418-1431. [CrossRef]

51. Liu, C.; Atanasov, K.E.; Tiburcio, A.F.; Alcázar, R. The polyamine putrescine contributes to H2O2 and RbohD/F-dependent positive feedback loop in Arabidopsis PAMP-triggered immunity. Front. Plant Sci. 2019, 10, 894. [CrossRef]

52. Brandstatter, I.; Kieber, J.J. Two genes with similarity to bacterial response regulators are rapidly and specifically induced by cytokinin in Arabidopsis. Plant Cell 1998, 10, 1009-1019. [CrossRef]

53. Werner, T.; Motyka, V.; Laucou, V.; Smets, R.; Van Onckelen, H.; Schmülling, T. Cytokinin-deficient transgenic Arabidopsis plants show multiple developmental alterations indicating opposite functions of cytokinins in the regulation of shoot and root meristem activity. Plant Cell 2003, 15, 2532-2550. [CrossRef]

54. Werner, T.; Köllmer, I.; Bartrina, I.; Holst, K.; Schmülling, T. New insights into the biology of cytokinin degradation. Plant Biol. 2006, 8, 371-381. [CrossRef]

55. Werner, T.; Motyka, V.; Strnad, M.; Schmülling, T. Regulation of plant growth by cytokinin. Proc. Natl. Acad. Sci. USA 2001, 98, 10487-10492. [CrossRef]

56. Werner, T.; Hanus, J.; Holub, J.; Schmülling, T.; Van Onckelen, H.; Strnad, M. New cytokinin metabolites in IPT transgenic Arabidopsis thaliana plants. Physiol. Plant 2003, 118, 127-137. [CrossRef]

57. Laplaze, L.; Benkova, E.; Casimiro, I.; Maes, L.; Vanneste, S.; Swarup, R.; Weijers, D.; Calvo, V.; Parizot, B.; Herrera-Rodriguez, M.B.; et al. Cytokinins act directly on lateral root founder cells to inhibit root initiation. Plant Cell 2007, 19, 3889-3900. [CrossRef] 
58. Gao, S.; Fang, J.; Xu, F.; Wang, W.; Sun, X.; Chu, J.; Cai, B.; Feng, Y.; Chu, C. Cytokinin oxidase/dehydrogenase4 Integrates cytokinin and auxin signaling to control rice crown root formation. Plant Physiol. 2014, 165, 1035-1046. [CrossRef]

59. Reid, D.E.; Heckmann, A.B.; Novák, O.; Kelly, S.; Stougaard, J. Cytokinin oxidase/dehydrogenase3 maintains cytokinin homeostasis during root and nodule development in Lotus japonicus. Plant Physiol. 2016, 170, 1060-1074. [CrossRef]

60. Dello Ioio, R.; Linhares, F.S.; Scacchi, E.; Casamitjana-Martinez, E.; Heidstra, R.; Costantino, P.; Sabatini, S. Cytokinins determine Arabidopsis root-meristem size by controlling cell differentiation. Curr. Biol. 2007, 17, 678-682. [CrossRef]

61. Köllmer, I.; Novák, O.; Strnad, M.; Schmülling, T.; Werner, T. Overexpression of the cytosolic cytokinin oxidase/dehydrogenase (CKX7) from Arabidopsis causes specific changes in root growth and xylem differentiation. Plant J. 2014, 78, 359-371. [CrossRef]

62. Gälweiler, L.; Guan, C.; Müller, A.; Wisman, E.; Mendgen, K.; Yephremov, A.; Palme, K. Regulation of polar auxin transport by AtPIN1 in Arabidopsis vascular tissue. Science 1998, 282, 2226-2230. [CrossRef] [PubMed]

63. Blilou, I.; Xu, J.; Wildwater, M.; Willemsen, V.; Paponov, I.; Friml, J.; Heidstra, R.; Aida, M.; Palme, K.; Scheres, B. The PIN auxin efflux facilitator network controls growth and patterning in Arabidopsis roots. Nature 2005, 433, 39-44. [CrossRef] [PubMed]

64. Hummel, I.; Bourdais, G.; Gouesbet, G.; Couée, I.; Malmberg, R.L.; El Amrani, A. Differential gene expression of arginine decarboxylase ADC1 and ADC2 in Arabidopsis thaliana: Characterization of transcriptional regulation during seed germination and seedling development. N. Phytol. 2004, 163, 519-531. [CrossRef]

65. Chang, S.C.; Kaufman, P.B.; Kang, B.G. Changes in Endogenous levels of free polyamines during petiole elongation in the semiaquatic plant Ranunculus sceleratus. Int. J. Plant Sci. 1999, 160, 691-697. [CrossRef]

66. Locke, J.M.; Bryce, J.H.; Morris, P.C. Contrasting effects of ethylene perception and biosynthesis inhibitors on germination and seedling growth of barley (Hordeum vulgare L.). J. Exp. Bot. 2000, 51, 1843-1849. [CrossRef]

67. Ha, B.H.; Cho, K.J.; Choi, Y.J.; Park, K.Y.; Kim, K.H. Characterization of arginine decarboxylase from Dianthus caryophyllus. Plant Physiol. Biochem. 2004, 42, 307-311. [CrossRef]

68. Ziosi, V.; Bregoli, A.M.; Bonghi, C.; Fossati, T.; Biondi, S.; Costa, G.; Torrigiani, P. Transcription of ethylene perception and biosynthesis genes is altered by putrescine, spermidine and amino ethoxyvinyl glycine (AVG) during ripening in peach fruit (Prunus persica). N. Phytol. 2006, 172, 229-238. [CrossRef]

69. Stes, E.; Biondi, S.; Holsters, M.; Vereecke, D. Bacterial and plant signal integration via D3-type cyclins enhances symptom development in the Arabidopsis-Rhodococcus fascians interaction. Plant Physiol. 2011, 156, 712-725. [CrossRef]

70. Tsukagoshi, H. Defective root growth triggered by oxidative stress is controlled through the expression of cell cycle-related genes. Plant Sci. 2012, 197, 30-39. [CrossRef]

71. Tsukagoshi, H. Control of root growth and development by reactive oxygen species. Curr. Opin. Plant Biol. 2016, 29, 57-63. [CrossRef]

72. Yamada, M.; Han, X.; Benfey, P.N. RGF1 controls root meristem size through ROS signalling. Nature 2020, 577, 85-88. [CrossRef]

73. Gonzalez, M.E.; Marco, F.; Minguet, E.G.; Carrasco-Sorli, P.; Blázquez, M.A.; Carbonell, J.; Ruiz, O.A.; Pieckenstain, F.L. Perturbation of spermine synthase gene expression and transcript profiling provide new insights on the role of the tetraamine spermine in Arabidopsis defense against Pseudomonas viridiflava. Plant Physiol. 2011, 156, 2266-2277. [CrossRef] [PubMed]

74. Kakehi, J.; Kuwashiro, Y.; Niitsu, M.; Takahashi, T. Thermospermine is required for stem elongation in Arabidopsis thaliana. Plant Cell Physiol. 2008, 49, 1342-1349. [CrossRef]

75. Couée, I.; Hummel, I.; Sulmon, C.; Gouesbet, G.; El Amrani, A. Involvement of polyamines in root development. Plant Cell. Tissue Organ Cult. 2004, 76, 1-10. [CrossRef]

76. Perilli, S.; Sabatini, S. Analysis of root meristem size development. In Plant Developmental Biology: Methods and Protocols; Hennig, L., Köhler, C., Eds.; Humana Press: Totowa, NJ, USA, 2010; pp. 177-187.

77. Ivanov, V.B.; Dubrovsky, J.G. Longitudinal zonation pattern in plant roots: Conflicts and solutions. Trends Plant Sci. 2013, 18, 237-243. [CrossRef] [PubMed]

78. Napsucialy-Mendivil, S.; Alvarez-Venegas, R.; Shishkova, S.; Dubrovsky, J.G. Arabidopsis homolog of trithorax1 (ATX1) is required for cell production, patterning, and morphogenesis in root development. J. Exp. Bot. 2014, 65, 6373-6384. [CrossRef]

79. Schmittgen, T.D.; Livak, K.J. Analyzing real-time PCR data by the comparative C(T) method. Nat. Protoc. 2008, 3, 1101-1108. [CrossRef]

80. Gong, X.; Liu, J.-H. Detection of free polyamines in plants subjected to abiotic stresses by high-performance liquid chromatography (HPLC). In Plant Stress Tolerance: Methods and Protocols; Sunkar, R., Ed.; Springer: New York, NY, USA, 2017 ; pp. 305-311. 